Volume 4 No. 3 Juli 2019

p-ISSN: 2477-8192 dan e-ISSN: 2502-2776

\title{
PERSEPSI MASYARAKAT KERUSAKAN TERHADAP EKOSISTEM MANGROVE DI WILAYAH PANTAI DESA LATA, KABUPATEN NAPANO KUSAMBI, KABUPATEN MUNA BARAT
}

\author{
Kartini $^{1}$, La Harudu ${ }^{2}$ \\ ${ }^{1}$ Program Studi Pendidikan Geografi \\ Universitas Halu Oleo \\ Email: kartinitiny95@gmail.com \\ ${ }^{2}$ Program Studi Pendidikan Geografi \\ Universitas Halu Oleo \\ Email: kartinitiny95@gmail.com
}

(Received: 4 Mei 2019; Reviewed: 11 Mei 2019; Accepted: 8 Juli; Published: 9 Juli 2019)

(C)2019 - Jurnal Penelitian Pendidikan Geografi. Ini adalah artikel dengan kses terbuka dibawah licenci CC BY-NC-4.0 (http://creativecommons.org/licenses/by-nc/4.0).

\begin{abstract}
Mangrove in the village of Latawe suffered severe damage, the community did not understand the importance of mangrove forests. There needs to be an assessment of the perceptions and factors of mangrove damage in the village of Latawe.Research purposes (1). To find out public perceptions about the severity of mangrove ecosystems in the coastal area of Latawe Village. (2). To find out the factors that affect damage to the mangrove ecosystem in the coastal area of Latawe Village. This research is descriptive qualitative research. The results of the study illustrate that (1). Community perceptions about the condition of mangrove forest ecosystems located on the coast of Latawe Village continue to experience damage and shrinkage of mangrove forests because they are used by the community in various needs such as the utilization of mangrove forests to fuel wood, the manufacture of fishing, building materials. (2). Factors that influence the cause of damage to mangrove forest ecosystems in the coastal area of Latawe Village include the low level of education of the community, low knowledge and low understanding of the community, low public awareness of environmental sustainability, high conversion rates to fishponds, the use of forest area settlements, and changes in the use of mangrove forests to become commercial as firewood.
\end{abstract}

Keywords: Perception, Mangrove Ecosystem, Environmental preservation, Latawe

\begin{abstract}
ABSTRAK
Mangrove di Desa Latawe mengalami kerusakan yang begitu parah, masyarakat tidak memahami betapa pentingnya hutan mangrove. Perlu adanya pengkajian terkait persepsi dan faktor kerusakan mangrove di desa Latawe. Tujuan penelitian: (1). Untuk mengetahui persepsi masyarakat tentang keruskan ekosistem mangrove di wilayah pesisir Desa Latawe. (2). Untuk mengetahui faktor-faktor yang mempengaruhi kerusakan ekosistem mangrove diwilayah pesisir Desa Latawe. Penelitian ini adalah penelitian yang bersifat kualitatif deskripstif. Adapun hasil penelitian menggambarkan bahwa (1). Persepsi masyarakat tentang kondisi ekosistem hutan mangrove yang berada di pesisir pantai Desa Latawe terus mengalami kerusakan dan penyusutan pupulasi hutan mangrove karena dimanfaatkan oleh masyarakat dalam berbagai kebutuhan seperti pemanfaatan hutan mangrove menjadi kayu bakar, pembuatan penangkap ikan, bahan bangunan. (2). Faktor faktor yang mempengaruhi sebagai menyebab kerusakan ekosistem hutan mangrove di wilayah pesisir Desa Latawe mencakup masih rendahnya tingkat pendidikan masyarakat, rendahnya pengetahuan dan pemahaman masyarakat yang rendah, kepedulian masyarakat yang rendah terhadap kelestarian
\end{abstract}


lingkungan, tingginya tingkat konversi menjadi lahan tambak, pemanfaatan kawasan hutan menjadi lokasi pemukiman, dan perubahan pemanfaatan hutan mangrove menjadi komersial sebagai kayu bakar.

Kata Kunci: Persepsi, Ekosistem Mangrove, Kelestarian lingkungan, Latawe

\section{PENDAHULUAN}

Ekosistem mangrove adalah tipe hutan yang khas terdapat di sepanjang pantai atau muara sungai yang dipengaruhi oleh pasang surut air laut. Mangrove banyak dijumpai di wilayah pesisir yang terlindung dari gempuran ombak dan daerah yang landai. Mangrove tumbuh optimal di wilayah pesisir yang memiliki muara sungai besar dan delta yang aliran airnya banyak mengandung lumpur. Sedangkan di wilayah pesisir yang tidak bermuara sungai, pertumbuhan vegetasi mangrove tidak optimal. Mangrove sulit tumbuh di wilayah pesisir yang terjal dan berombak besar dengan arus pasang surut kuat, karena kondisi ini tidak memungkinkan terjadinya pengendapan lumpur yang diperlukan sebagai substrat bagi pertumbuhannya (Dahuri, 2013).

Menurut Kustanti (2011), secara fisik hutan mangrove memiliki peranan penting dalam melindungi pantai dari gelombang besar, angin kencang, badai, dan lain sebagainya. Secara ekologis ekosistem mangrove memiliki nilai penting sebagai penyedia makanan bagi organisme yang tinggal disekitar mangrove, seperti udang, kepiting, ikan, burung, dan mamalia. Selain itu pada ekosistemhutan mangrove terdapat beragam jenis sumberdaya hayati yang dapat dimanfaatkan untuk kesejahteraan manusia. Misalnya saja yang dapat diperoleh dari hutan mangrove adalah kayu untuk bahan bangunan, kayu bakar, bahan arang, produk hutan mangrove dapat diolah peralatan rumah tangga, dan bahan baku tekstil. Sehubungan dengan besarnya manfaat ekosistem hutan mangrove secara ekologis dan ekonomis, ekosistem hutan mangrove harus di pertahankan keberadaannya.

Kondisi ini dilihat pada kenyataan bahwa aktivitas manusia yang langsung berinteraksi dengan hutan bakau banyak menimbulkan persoalan lingkungan yang mendesak dan kompleks yang mempertaruhkan kelangsungan hidup manusia, yaitu terjadinya abrasi, degradasi habitat, bencana alam dan lain sebagainya, (Agus, 2012). Selain itu kita dihadapkan krisis ekosistim pantai yang intensitas dan kompleksitasnya tak terkira. Perusakan terhadap ekosistem mangrove terjadi dimanamana dan mengancam seluruh jaringan kehidupan pesisir. Perilaku masyarakat telah menjadi penyebab utamanya. Lebih khusus lagi, kerusakan hutan (mangrove) sebagian besar disebabkan olehadanya aktivitas masyarakat yang mengkonversi hutan mangrove menjadi pertambakan, permukiman, perkebunan kelapa, pembangunan pasar, pelabuhan, dan pembangunan industri. Berdasarkan uraian permasaalahan di atas maka menarik untuk dibahas lebih lanjut tentang persepsi masyarakat tentang kerusakan hutan mangrove di wilayah pesisir desa Latawe dan faktor-faktor yang mempengaruhi kerusakan ekosistem mangrove.

Berdasarkan uraian di atas maka penting untuk mendeskripsikan berbagai tinjauan teoritis dalam pembahasan ini menyangkut persepsi masyarakat desa Latawe tentang kerusakan hutan mangrove di wilayah pesisir desa Latawe dan faktor-faktor yang mempengaruhi kerusakan ekosistem mangrove.

Menurut (Sugihartono, 2013). Persepsi merupakan kemampuan otak dan menerjemahkan stimulus atau proses untuk menerjemahkan stimulus yang masuk kedalam indra manusia. Persepsi manusia terdapat perbedaan sudut pandang dalam pengindraan. Ada yang mempersepsikan sesuatu itu baik atau persepsi yang positif maupun persepsi yang negatigf yang akan mempengaruhi tindakan manusia yang tampak atau nyata. Stimulus dalam persepsi dapat datang dari luar, tetapi juga dapat datang dalam dari individu itu sendiri. Stimulus sebagian besar datang dari luar individu yang bersangkutan. Sekalipun persepsi dapat melalui macam-macam alat indera penglihatan (Walgito, 2010).

Menurut Soegiarto wilayah pesisir yang digunakan di Indonesia adalah Daerah pertemuan antara daratan dan laut; kearah darat wilayah pesisir meliputi arah daratan, baik kering maupun terendam air, yang masih dipengaruhi sifat-sifat laut seperti pasang surut, angin laut, dan perembesan air asin; 
sedangkan kearah laut wilayah pesisir mencakup bagian laut yang masih dipengaruhi oleh proses-proses alami yang terjadi didarat seperti sedientasi dan aliran air tawar, maupun yang disebabkan oleh kegiatan manusia di darat seperti penggundulan hutan dan pencemaran.

Sedangkan menurut kesepakatan internasional, wilayah pesisir didefinisikan sebagai wilayah peralihan antara laut dan daratan, kearah darat mencakup daerah yang masih terkena pengaruh percikan air laut atau pasang surut, dan kearah laut meliputi daerah paparan benua. Berdasarkan UU No. 1 tahun 2014 tantang Pengelolaan Wilayah Pesisir dan Pulau-pulau Kecil, wilayah pesisir dan perairan adalah daerah peralihan antara Ekosistem darat dan laut yang dipengaruhi oleh perubahan didarat dan laut. Sedangkan perairan pesisir adalah laut yang berbatasan dengan daratan meliputi perairan sejauh $12 \mathrm{mil}$ laut diukur dari garis pantai, perairan yang menghubungkan pantai dan pulau-pulau, estuary, teluk, perairan dangkal, rawa payau, dan laguna.

Pembahasan lain dalam tulisan ini adalah Berkaitan dengan hutan mangrove. Mangrove adalah vegetasi hutan yang tumbuh pada tanah aluvial pada pantai dan sekitar muara sungai yang dipengaruhi oleh pasang surut air laut. Mangrove juga tumbuh pada pantai karang atau daratan terumbu karang yang berpasir tipis atau pada pantai berlumpur (Kordi, 2012.)

\section{METODE PENELITIAN}

Jenis penelitian ini adalah penelitian kualitatif, yaitu penelitian yang lebih mengarah pada pengungkapan suatu keadaan yang sebagaimana adanya yang mengungkapkan fakta-fakta yang ada. Hasil penelitian ini lebih difokuskan agar dapat memberikan gambaran sebenarnya dari obyek yang akan diteliti, yaitu persepsi masyarakat tentang kerusakan lingkungan ekosistem mangrove dan faktor yang mempengaruhinya di wilayah pesisir Desa Latawe. Adapun yang menjadi populasi dalam penelitian ini adalah masyarakat yang ada di Desa Latawe. Berdasarkan data yang ada di kantor Desa Latawe, sebanyak 321 Kepala Keluarga. Sedangkan sampel penelitian dilakukan metode Pemilihan sampel dilakukan dengan menggunakan sampel acak (random sampling) dengan penarikan sampel menggunakan rumus slovin yaitu:
$n=\frac{N}{1+N e^{2}}$

Keterangan:

(Sugiono, 2007)

$\mathrm{n}=$ Ukuran sampel

$\mathrm{N}=$ Ukuran populasi

$\mathrm{e}=$ Tingkat kesalahan dalam memilih anggota sampel yang ditolelir (tingkat kesalahan yang diambil dalam sampling ini adalah sebesar $10 \%$ )

$n=\frac{N}{1+N(0,1)^{2}}$

$n=\frac{310}{1+310(0,1)^{2}}$

$n=\frac{310}{4,1}$

$n=75,609$ dibulatkan jadi 76 Responden

\section{Waktu dan Tempat Penelitian}

Penelitian ini telah dilaksanakan pada Bulan Agustus 2018, bertempat di ekosistem mangrove Desa Latawe, Kecamatan Napano Kusambi, Kabupaten Muna Barat.

\section{Teknik Pengumpulan Data}

Teknik pengumpulan data dalam penelitian ini menggunakan langkah sebagai berikut :

1. Angket yaitu dilakukan dengan cara mengadakan daftar pertanyaan kepada responden dengan cara mencek (check list) jawaban yang sesuai dengan pendapat dari pada responden.

2. Wawancara dilakukan kepada informan penelitian dengan wawancara secara terpadu

3. Dokumentasi adalah bagian pendiskripsian berupa catatan tertulis dan gambar yang terdapat pada subjek/objek penelitian.

\section{Teknik Analisis data}

Teknik analisis data yang digunakan adalah teknik analisis deskriptif kualitatif, dimana penulis mendeskriptifkan hasil penelitian berdasarkan data yang didapatkan ketika penelitian dilokasi tersebut. Sebelum data hasil penelitian dianilisis, terlebih dahulu data-data diolah dengan teknik tabulasi dan editing untuk mempermudah analisis data. Penelitian ini merupakan jenis penelitian kualitatif sehingga teknik analisis data yang digunakan adalah teknik analisis kualitatif. 
Analisis data kualitatif merupakan tata cara penelitian yang menghasilkan data deskriptif, yaitu apa yangdinyatakan oleh responden secara tertulis maupun lisan, dan perilaku nyata. Oleh karena itu, pengolahan data dilakukan dengan cara menggolongkan data berdasarkan sifat atau jenisnya, selain itu proses penglolahan dapat juga dilakukan dengan skoring dan tabulasi data.

\section{HASIL PENELITIAN}

\section{Karakterisrik Reponden Penelitian}

1. Kriteria Responden Berdasarkan Umur

Umur merupakan usia responden pada saat dilakukan penelitian yang dihitung dalam satuan tahun. Umur Responden dapat mempengaruhi produktifitas seseorang karena erat kaitannya dengan kemampuan kerja dan juga pola pikir untuk menerima dan menentukan bentuk serta manajemen yang diterapkan dalam suatu usaha. Berdasarkan Rata-rata umur di Desa Latawe dapat dilihat pada Tabel berikut.

Tabel 1. Klasifikasi Umur Responden di Latawe Kecamatan Napano Kusambi

\begin{tabular}{cccc}
\hline No. & $\begin{array}{c}\text { Klasifikasi Umur } \\
\text { (Tahun) }\end{array}$ & $\begin{array}{c}\text { Jumlah Responden } \\
\text { (orang) }\end{array}$ & $\begin{array}{c}\text { Persentase } \\
(\boldsymbol{\%})\end{array}$ \\
\hline 1. & $20-35$ & 25 & 32.89 \\
2. & $35-50$ & 35 & 46.05 \\
3. & $>51$ & 16 & 21.05 \\
\hline & Jumlah & $\mathbf{7 6}$ & $\mathbf{1 0 0}$ \\
\hline
\end{tabular}

Sumber: Analisis Data Primer 2019.

Berdasarkan tabel di atas maka menunjukan bahwa kriteria responden berdasarkan umur dari 76 responden sebanyak 25 orang atau $32.89 \%$ yang berada pada kisaran umur 20 sampai 35 tahun dan sebanyak 35 orang atau sebanyak $46.05 \%$ yang berada pada kisaran umur 35 sampai 50 tahun sebanyak 16 orang atau sekitar $21.05 \%$ yang berada pada kisaran umur 51 tahun. Sehingga umur merupakan salah satu indikator kemampuan fisik seseorang.

\section{Kriteria Responden Berdasaran Tingkat Pendidikan}

Pendidikan yang memadai dapat membantu masyarakat dalam upaya peningkatan kapasitas diri. Hasil penelitian terhadap tingkat pendidikan responden di lokasi penelitian desa latawe dapat dilihat pada Tabel berikut:

Tabel 2. Klasifikasi Responden Berdasarkan Tingkat Pendidikan di Desa Latawe

\begin{tabular}{clcc}
\hline No. & \multicolumn{1}{c}{ Tingkat Pendidikan } & $\begin{array}{c}\text { Jumlah Responden } \\
\text { (orang) }\end{array}$ & $\begin{array}{c}\text { Persentase } \\
(\mathbf{\%})\end{array}$ \\
\hline 1. & Tidak Sekolah & 6 & 7.89 \\
2. & SD/Sederajat & 20 & 26.31 \\
3. & SMP/Sederajat & 20 & 26.31 \\
4. & SMA/ Sederajat & 20 & 26.31 \\
5. & Sarjana & 10 & 13.15 \\
\hline \multicolumn{5}{r}{ Jumlah } & $\mathbf{7 6}$ & $\mathbf{1 0 0}$ \\
\hline
\end{tabular}

Sumber: Analisis Data Primer 2019.

Berdasarkan tabel di atas menunjukan bahwa dalam pengambilan responden dalam penelitian ini dengan pertimbangan pengambilan responden secara proporsional maka berdasarkan tabel di atas telah berusaha didapatkan responden secara proporsional dengan berbagai tingkatan dalam pendidikan yaitu sebanyak 6 orang atau $7.89 \%$ tidak sekolah, 20 orang atau $26.31 \%$ responden pada tingkat pendidikan SD, 20 orang atau
$26.31 \%$ responden pada tingkat SMP, 20 orang atau $26.31 \%$ responden padatingkat SMA serta 10 orang atau sekitar $13.15 \%$ responden dengan tingkat pendidikan sarjana.

Persepsi Masyarakat Terhadap Ekosistem Mangrove Di desa Latawe Kecamatan Napano Kusambi

Pemanfaatan hutan mangrove secara keseluruhan masyarakat Kecamatan Napano 
Kusambi Desa Latawe umumnya mencakup pemanfaatan untuk keperluan rumah tangga, pengolahan pertanian tambak atau empang, keperluan kayu bakar, bahan alat bangunan dan lain-lain adapun lebih jelasnya tenatng kondisi dan keadaan hutan mangrove di desa

Tabel 3. Tanggapan Responden Terhadap Eksosistem Hutan Mangrove yang Semakin Berkurang dan Terjadi Penyusutan

\begin{tabular}{cccccll}
\hline No. & JawabaI & Frekuensi & Jumlah & Skor Rata-rat: & Kategori \\
\hline 1. & SS & 42 & 168 & & & \\
2. & S & 34 & 102 & 3.55 & Sangat & \\
3. & KS & 0 & 0 & & & \\
4. & TS & 0 & 0 & & & \\
\hline
\end{tabular}

Sumber: Analisis Data Primer 2019.

Berdasarkan tabel di atas menunjukan bahwa tanggapan responden terhadap kondisi populasi hutan mangrove di desa Latawe terus mengalami penyusutan dan kerusakan dari 76 responden berdasarkan hasil jawaban
Latawe Kecamatan Napano Kusambi berdasarkan hasil penelitian yang dilakukan peneliti dapat dijabarkan berdasarkan tanggapan responden dalam penelitian ini sebagai berikut: responden untuk jawaban sangat setuju yaitu sebanyak 42 dengan skor 168 , jawaban setuju sebanyak 34 dengan skor 102, dan jawaban Tidak setuju sebanyak 0 dengan skor 0 serta jawaban 0 dengan skor 0 .

Tabel 4. Tanggapan Responden Tentang Pemanfaatan Pohon Magrove untuk Keperluan Kayu Bakar

\begin{tabular}{cccccc}
\hline No. & Jawaban & Frekuensi & Jumlah & Skor Rata-rat: & Kategori \\
\hline 1. & SS & 13 & 52 & & \\
2. & S & 54 & 162 & 3.07 & Setuju \\
3. & KS & 9 & 18 & & \\
4. & TS & 0 & 0 & & \\
\hline & Jumlah & $\mathbf{7 6}$ & $\mathbf{2 3 4}$ & & \\
\hline
\end{tabular}

Sumber: Analisis Data Primer 2019.

Berdasarkan tabel di atas menunjukan bahwa tanggapan responden terhadap pemanfaatan hutan mangrove dengan sistim tebang habis sebagai bahan kayu bakar menybabkan kerusakan hutan mangrove dari 76 responden berdasarkan hasil jawaban

Tabel 5. Tanggapan Responden Terhadap Pemanfaatan Hutan Mangrove Sebagai Bahan Bangunan di Desa Latawe

\begin{tabular}{cccccc}
\hline No. & Jawaban & Frekuensi & Jumlah & Skor Rata-rat: & Kategori \\
\hline 1. & SS & 44 & 176 & & \\
2. & S & 44 & 132 & 2.86 & Kurang \\
3. & KS & 21 & 42 & & Setuju \\
4. & TS & 0 & 0 & & \\
\hline & Jumlah & $\mathbf{7 6}$ & $\mathbf{2 1 8}$ & & \\
\hline
\end{tabular}

Sumber: Analisis Data Primer 2019.

Berdasarkan tabel di atas menunjukan bahwa tanggapan responden terhadap pemanfaatan hutan mangrove sebagai bahan bangunan dari 76 responden berdasarkan hasil jawaban responden untuk jawaban sangat. responden untuk jawaban sangat setuju yaitu sebanyak 13 dengan skor 52, jawaban setuju sebanyak 54 dengan skor 162 , dan jawaban Tidak setuju sebanyak 9 dengan skor 18 serta jawaban 0 dengan skor 0 .

setuju yaitu sebanyak 38 dengan skor 152 , jawaban setuju sebanyak 28 dengan skor 84 , dan jawaban Tidak setuju sebanyak 10 dengan skor 20 serta jawaban 0 dengan skor 0 . 
Tabel 6. Tanggapan Responden Terhadap Pemanfaatan Hutan Mangrove Sebagai Lahan Pertanian Tambak di Desa Latawe

\begin{tabular}{cccccc}
\hline No. & Jawaban & Frekuensi & Jumlah & Skor Rata-rata & Kategori \\
\hline 1. & SS & 44 & 176 & & \\
2. & S & 44 & 132 & 2.86 & Kurang \\
3. & KS & 21 & 42 & & Setuju \\
4. & TS & 0 & 0 & & \\
\hline & Jumlah & $\mathbf{7 6}$ & $\mathbf{2 1 8}$ & & \\
\hline
\end{tabular}

Sumber: Analisis Data Primer 2019.

Berdasarkan tabel di atas menunjukan bahwa tanggapan responden terhadap pemanfaatan hutan mangrove sebagai bahan bangunan dari 76 responden berdasarkan hasil jawaban responden untuk jawaban sangat setuju yaitu sebanyak 38 dengan skor 152 , jawaban setuju sebanyak 28 dengan skor 84 , dan jawaban Tidak setuju sebanyak 10 dengan skor 20 serta jawaban 0 dengan skor 0 .

\section{PENUTUP}

\section{Kesimpulan}

Berdasarkan hasil pembahasan dan analisis dalam penelitian ini maka penulis memberikan kesimpulan sebagai berikut:

1. Persepsi masyarakat tentang ekosistim mangrove di pesisir pantai desa Latawe adalah menunjukan terus mengalami kerusakan dan penyusutan karena pupulasi hutan mangrove dimanfaatkan oleh masyarakat dalam berbagai kebutuhan seperti pemanfaatan hutan mangrove menjadi kayu bakar dengan tanggapan responden rata-rata nilai 3.07 atau kategori setuju, pemanfaatan hutan mangrove menjadi bahan bangunan dengan skor ratarata nilai 2.86 atau kategori kurang setuju, hutan mangrove dimanfaatkan sebagai lahan tambak dengan rata-rata nilai 3.18 atau kategori setuju. Berdasarkan data tersebut maka persepsi masyarakat tentang kerusakan ekosistem mangrove adalah rata-rata kategori setuju.

2. Faktor faktor yang menyebab kerusakan ekosistim hutan mangrove di wilayah pesisir desa Latawe mencakup masih rendahnya tingkat pendidikan masyarakat dengan nilai rata-rata 3.50 kategori sangat setuju, rendahnya pengetahuan dan pemahaman masyarakat dengan nilai rata-rata 3.51 atau sangat setuju, kepedulian masyarakat yang rendah terhadap kelestarian lingkungan dengan nilai rata-rata 3.14 atau kategori setuju, tingginya tingkat konversi menjadi lahan tambak dengan nilai rata-rata 3.56 atau sangat setuju, dan pemanfaatan kawasan hutan menjadi lokasi pemukiman dengan nilai rata-

rata 3.09 atau setuju, serta peningkatan komersialisasi hutan bakau menjadi bahan kayu bakar dengan nilai rata-rata 3.10 atau kategori setuju. Berdasarkan data tersebut maka secara umum tanggapan responden tentang faktor penyebab kerusakan hutan mangrove adalah kategori setuju bahkan sangat setuju

\section{Saran}

Sebuah penelitian pada hakikatnya adalah dapat memberikan manfaat. Adapun lebih jelasnya saran dalam penelitian ini adalah sebagai berikut:

1. Kepada pihak Pemerintah

Untuk memberikan perhatian serius kepada peningkatan kualitas sumber daya manusia agar meningkatkan pengetahuan tentang pentingnya kelestarian lingkungan hidup

2. Kepada Masyarakat

Agar lebih meningkatkan kesadaran terhadap pentingnya menjaga kelestarian lingkungan hidup karena sebagai tempat hidup yang saling ketergantungan antara manusia dan lingkunganya sebagai tempat hidup.

3. Insan Akademik

Untuk terus melakukan penelitian lanjutan tentang upaya dalam meningkatkan kesadaran masyarakat pesisir agar memimiliki kesadaran dalam mengelola dan melestarikan lingkungan hidup agar terus berkelanjutan.

\section{DAFTAR PUSTAKA}

Aris Purwoko, 2012. Peningkatan Keterampilan Berbicara Melalui Metode Debat Aktif Pada Mata Pelajaran Bahasa Indonesia Siswa Kelas V SDN 3 Purwantoro Kecamatan Purwantoro Kabupaten Wonogiri Tahun Ajaran 2011/2012. Skripsi. Surakarta: UMS

Damayatanti, 2011. Upaya Pelestarian Hutan melalui Pengelolaan Sumberdaya Hutan Bersama Masyarakat. Jurnal Interntional Journal of Indonesian Society And Culture.Volume 3 No. 1. 
Dahuri, Rokhmin, dkk (2013). Sumber Daya Wilayah Pesisir dan Lautan Secara Terpadu. Jakarta: Balai Pustaka.

Kustanti, A. 2011. Manajemen Hutan Mangrove. Bogor: Institut Pertanian Bogor.

Kordi, K. Guhufran H. 2012. Ekosistem Mangrove, Potensi, Fungsi, dan Pengelolaan. Jakarta: Rineka Cipta.

Sugiono. 2007. Metode Penelitian Kuantitatif Kualitatif dan $R \& D$. Bandung: Alfabeta.
Sugihartono, dkk. 2013. Psikologi Pendidikan. Yokyakarta: UNY Press.

Walgito, B. 2010. Pengantar Psikologi Umum. Yokyakarta: Andi offset.

Pengelola Jurnal Penelitian Pendidikan Geografi La Ode Amaluddin

Gedung FKIP Lt. 2 Universitas Halu Oleo.

Kampus Bumi Tridharma Anduonohu Kendari93232

Email: amaluddin.75@gmail.com 